\title{
Effects of Gestational Exposure to Monoamine Oxidase Inhibitors in Rats: Preliminary Behavioral and Neurochemical Studies
}

\author{
Patricia M. Whitaker-Azmitia, Ph.D., Xini Zhang, Ph.D., and Colin Clarke, B.Sc.
}

\begin{abstract}
Monoamine neurotransmitters are important in the development of the immature mammalian brain, prior to assuming their role as neurotransmitters. The endogenous levels of these transmitters are highly regulated by the enzyme monoamine oxidase (MAO). Thus, any change in this enzyme should have a profound effect on brain development. In order to test this hypothesis, we treated developing rat pups with the monoamine oxidase inhibitors (MAO-Is), clorgyline (MAO-A, $3 \mathrm{mg} / \mathrm{kg})$, and deprenyl (MAO-B, $3 \mathrm{mg} / \mathrm{kg})$ throughout gestation (MAO-I-birth), or throughout gestation and to sacrifice (MAO-I-sac). The animals were analyzed for serotonin and dopamine terminal density, using ${ }^{3} \mathrm{H}$-paroxetine and ${ }^{3} \mathrm{H}-\mathrm{GBR} 12935$, respectively. Whereas there were no changes in the development of the dopamine system, the serotonin system was severely
\end{abstract}

KEYWORDS: Serotonin; Monoamine oxidase; Monoamine oxidase inhibitors; Deprenyl; Clorgyline;

Neurodevelopment; Impulsivity; Hyperactivity; Norrie's disease.

Development of the mammalian central nervous system is dependent upon a variety of chemical substances, which must occur in the right amount, and at the right time for development to take place properly. Included

From the Department of Psychiatry and BehavioralSciences, SUNY, Stony Brook, NY.

Address reprint requests to Professor Patricia M. Whitaker-Azmitia, Associate Professor of Psychiatry, Department of Psychiatry and Behavioral Sciences, State University of New York at Stony Brook, Stony Brook, NY 11794-8101.

Received March 21, 1994; accepted May 3, 1994. affected, particularly in the cortex that showed a significant reduction of innervation at 30 days postnatal. The animals reached all normal development milestones on schedule, and had no changes in measures of anxiety (\% light/dark); however, the animals showed increased open field activity and deficits in a passive avoidance paradigm, which may be a measure of impulsivity. The MAO-I-sac animals were severely impaired, showing stereotypic behavior, seizures, and eventually visual impairments. Our results are discussed in terms of relevance to human disease states, such as atypical Norrie's disease, impulsivity, and hyperactivity. As well, our results should be used to caution against the use of MAO-Is in women of child-bearing age.

[Neuropsychopharmacology 11:125-132, 1994]

among these substances are the monoamine neurotransmitters - serotonin, dopamine, and noradrenaline (Whitaker-Azmitia 1992); thus, any circumstance that changes the amount of these neurotransmitters in the developing brain can drastically alter the final structure and function of that brain. For example, if the enzyme responsible for degradation of these neurotransmitters were lacking, the levels of the transmitters might become very high and damage the brain.

Monoamine oxidase (MAO) is the major enzyme responsible for degradation of these biogenic amines, and for the trace amines, phenylethylamine and tyramine. MAO is distributed throughout the periphery, as well as the brain, and occurs in two forms, MAO-A and MAO-B, which can be differentiated on the basis of their cellular distribution, their substrate specifıcity, 
and their inhibitor specificity. MAO-A occurs in highest levels in catecholaminergic neurons (Fowler et al. 1987), although it is the form with the greatest affinity for serotonin. MAO-B occurs mostly in serotonergic neurons and astroglial cells (Fowler et al. 1987). The catecholamines, dopamine, noradrenaline, and adrenaline, are metabolized with equal affinity by both forms of the enzyme. The trace amines, tyramine and phenylethylamine, are metabolized with greatest affinity by MAO-A and MAO-B, respectively (Murphy 1978). In the adult human brain, MAO-B is the more predominant form (Garrick and Murphy 1980).

There are conditions in which human fetuses could have lowered activity of $\mathrm{MAO}$, and thus be exposed to potentially toxic levels of their own or maternal biogenic amines. It is possible that women while being treated for depression with MAO-I's could become pregnant. There are also genetic diseases that would cause lowered MAO activity-for example, atypical Norrie's disease - and an apparent MAO-A deficiency state (Brunner et al. 1993). Norrie's disease is an X-linked recessive disorder that leads to blindness, mental retardation, seizures, and other neurological and physical symptoms. Recent evidence has shown that some of the more severely affected patients have complete deletions of the genes for monoamine oxidase $\mathrm{A}$ and monoamine oxidase $B$. There are other human diseases in which the activity of MAO may be decreased. For example, children with attentional deficit disorder have lowered platelet MAO activity (Shekim et al. 1986), adult alcoholics (Sherif et al. 1992), and adults with aggressive impulse disorders (Brunner et al. 1993).

The current study was undertaken to determine how profound the effects of lowered MAO activity could be to the developing rat brain. The MAO activity was lowered by the combined use of two MAO inhibitors, clorgyline (an MAO-A inhibitor) and deprenyl (an MAO-B inhibitor), throughoutgestation. Some rat pups received no further treatment after birth (MAO-I-birth). Rat pups are born precociously compared to humans, and their time of birth is often equated to the first trimester of human development. These pups may therefore represent exposure to lowered MAO activity only during the first trimester of human pregnancy, which may be the case in a woman who stops treatment with an MAO-I on learning she is pregnant. Other rat pups were treated throughout life (MAO-I-sac), to represent the developing human in which levels of MAO are decreased by genetic or other factors.

\section{METHODS AND MATERIALS}

\section{Treatment of Animals}

Sixteen virgin Sprague-Dawley female rats (Taconic Farms, New York) weighing $150 \mathrm{~g}$ to $200 \mathrm{~g}$ were studied, four in each of the four treatment groups. The animals were allowed free access to food and water, housed at constant room temperature $\left(20-22^{\circ} \mathrm{C}\right)$, and exposed to a light cycle of twelve hours daily (1300-0100 hours) for one week prior to the experiment commencement. Female rats were housed with male rats at 0900 hours ( 8 hours into their darkcycle), and were observed for mating behavior. The day that mating behavior was noted was designated day one of gestation. All drug administration to the dams began on the second day of gestation and continued daily until parturition. Solutions containing both MAO-Is, were delivered in a volume of $1 \mathrm{ml} / \mathrm{kg}$ body weight, approximate volumes of $0.150 \mathrm{ml}$ to $0.38 \mathrm{ml}$ at term. Clorgyline $(3 \mathrm{mg} / \mathrm{kg}$, Research Biochemicals, Inc.) and deprenyl $(3 \mathrm{mg} / \mathrm{kg}$, Research Biochemicals, Inc.) were given, subcutaneously, into the nape of the neck. The pregnant dams were weighed daily, and the total gestation time was recorded.

At birth, litters were culled to eight, and the pups remained with their dams, to give a total of 32 pups in each treatment group, or 128 in the complete study. Pups were weighed twice weekly, after any behavioral testing, and prior to any treatment. Rat pups in the MAO-I-sac group were injected subcutaneously with clorgyline $(3 \mathrm{mg} / \mathrm{kg}$ ) and deprenyl ( $3 \mathrm{mg} / \mathrm{kg})$ daily, from the day of birth until sacrifice. The time of incisor eruption and eye-opening was recorded. The sex of each pup was noted at the time of testing, and the final data analyzed for sex differences.

\section{Behavioral Studies}

Catalepsy. Five-day-old animals were removed from their dam's cage and housed with their littermates on a heated pad immediately prior to the commencement of the test. Animals were selected at random and placed in a reclined position with one hindpaw resting on a platform elevated $0.5 \mathrm{~cm}$ above the test cage floor. Animals maintaining this position for a period of thirty seconds were considered cataleptic.

Righting Reflex. Five-day-old animals were removed from their dam's cage and housed with their littermates on a heated pad immediately prior to the test commencement. Pups were placed on their backs and the time for the pup to completely right itself was recorded. Each pup was tested three times, and the mean time to righting itself was calculated.

Olfaction. Five-day-old rat pups were removed from their dams, and tested individually for a response to a cotton ball saturated with distilled water or saturated with $10 \%$ ammonia. Pups were placed with their nose $2 \mathrm{~cm}$ from the cotton ball and were scored as positive or negative responses depending on whether or not they moved their heads away from the odor within $2 \mathrm{sec}$. 
Percent Light/Dark. Trials were conducted in a chamber $(0.5 \times 0.5 \times 0.25 \mathrm{~m})$ separated evenly by a dividing wall. Half of the chamber was open and lit by ambient lighting, the other half was enclosed and dark. An opening in the dividing wall $(10 \mathrm{~cm} \times 5 \mathrm{~cm})$ allowed free movement of the animals between chambers. Animals were removed from their dam's cage and housed with their littermates on a heated pad immediately prior to the test. Time spent in each chamber was recorded during a five minute test interval, and the final results expressed as a percentage of darktime. Animals were tested between 0900 and 1100 hours on PD 25.

Passive Avoidance. We have previously determined that manipulations of the serotonergic system may result in altered pain sensitivity. As a result, we have developed a novel passive avoidance paradigm that does not use pain as the negative reinforcer. Animals were trained and tested in the passive avoidance apparatus, which consisted of a box measuring $50 \times 50 \times 25 \mathrm{~cm}$ and evenly divided into two chambers, one was lit with a40-watt bulb, whereas the other was covered and dark. The animal was able to exit from the first chamber into the second, through a $10 \times 5 \mathrm{~cm}$ opening. The second chamber had a nonsupporting floor that was spatially situated $0.25 \mathrm{~m}$ above the surface of a basin $(0.5 \times$ $0.5 \times 0.5 \mathrm{~m})$ of water $\left(24^{\circ} \mathrm{C}\right)$. As the animal entered the second chamber, it fell into the basin. The animal was removed from the basin of water after 30 seconds. Animals were trained on PD 23, tested on PD 24, and recorded for the latency (in seconds) to enter the second chamber. An animal that increased the latency by more than 10 seconds on PD 24 was considered to have successfully shown passive avoidance. Animals were tested between 0900 and 1200 hours. Animals used in this paradigm were excluded from all further neurochemical and behavioral analysis.

Open Field Behavior. Animals were removed from their dam's cage and housed with their littermates on aheated pad immediately prior to the test commencement. Animals were randomly selected and placed individually in a testing arena consisting of a $75 \mathrm{~cm} \times$ $75 \mathrm{~cm} \times 25 \mathrm{~cm}$ opaque enclosure with a $4 \mathrm{~cm} \times 4 \mathrm{~cm}$ painted floor grid. An experimenter, blind to the animal's treatment, counted the number of grid lines crossed by the animal during a five min test period. Animals were tested between $0900 \mathrm{hrs}$ and $1200 \mathrm{hrs}$ on PD 16 and on PD 30.

\section{Neurochemical Analysis}

The number of specific neurotransmitter uptake sites was determined using saturation (Scatchard) analysis of direct binding assays of radiolabelled uptake inhibitors on PD 5, PD 15, and PD $30 .{ }^{3} \mathrm{H}$-paroxetine was used to determine serotonin terminal density, and ${ }^{3} \mathrm{H}$ -
GBR 12935 was used to determine dopamine terminal density.

Tissue Preparation. The brains were rapidly removed, bluntly dissected into specific brain regions, and homogenized into $50 \mathrm{vol}$ of the appropriate buffer under each radiolabel. The homogenate was centrifuged at $30,000 \mathrm{~g}$ for $10 \mathrm{~min}$ and resuspended in 10 vol of buffer. The final tissue suspension was frozen at $-70^{\circ} \mathrm{C}$ until use.

Binding Assay. For the assay, the tissue was incubated in triplicate with six different concentrations of radiolabel. After incubation, the samples were harvested through Whatman GF/B filters, precoated with $0.05 \%$ polyethylenimine, using a PHD cell harvester (Cambridge Instruments). The filters were washed with two $5 \mathrm{ml}$ volumes of buffer and removed into scintillation vials containing $5 \mathrm{ml}$ Scintiverse. Radioactivity was counted in a LKB Rackbeta (counting efficiency 43\%). Binding kinetics $\left(B_{\max }\right.$ and $\left.K_{D}\right)$ were determined by Scatchard analysis. Protein determination was by the Lowry method.

${ }^{3}$ H-Paroxetine: Serotonin Uptake Sites. The tissue $(400 \mu \mathrm{l})$ from hippocampus, caudate, and cortex was incubated at $22^{\circ} \mathrm{C}$ for one hour with $100 \mu \mathrm{l}$ buffer (50 $\mathrm{mM}$ Tris, $120 \mathrm{mM} \mathrm{NaCl}, 5 \mathrm{mM} \mathrm{KCl}$, and $0.1 \%$ ascorbic acid; pH 7.3), or buffer containing $1 \mu \mathrm{M}$ final concentration fluoxetine, and $500 \mu \mathrm{l}^{3} \mathrm{H}$-paroxetine (New England Nuclear, $28.6 \mathrm{Ci} /$ mmole; final concentration 0.05 , $0.1,0.5,1.0,1.5$ and 2.0).

${ }^{3}$ H-GBR 12935: Dopamine Uptake Sites. The tissue $(400 \mu \mathrm{l})$ from caudate and cortex was incubated with $200 \mu \mathrm{l}^{3} \mathrm{H}-\mathrm{GBR}-12935$ (New England Nuclear, Specific Activity $34 \mathrm{Ci} / \mathrm{mmole}$; final concentration $0.5,1.0,2.0$, $5.0,10$, and $25 \mathrm{nM})$, and $100 \mu \mathrm{l}$ buffer $(50 \mathrm{mM}$ Tris $\mathrm{HCl}$, $120 \mathrm{mM} \mathrm{NaCl}, 4 \mathrm{nM} \mathrm{MgCl} 2,0.1 \%$ ascorbate; $\mathrm{pH} \mathrm{7.4),}$ or buffer containing final concentration of $1 \mu \mathrm{M}$ GBR 12909 for one hour at $4^{\circ} \mathrm{C}$.

MAO Activity. The activity of MAO in the brain tissue was determined at PD 5 using $40 \mu \mathrm{M}$ [ethyl- ${ }^{3} \mathrm{H}$ ] tryptamine $(25.5 \mathrm{Ci} / \mathrm{mmole}$; NEN) by the toluene extraction method(Wurtman and Axelrod 1963; Edelstein and Breakefield 1986).

Data Analysis. The data was analyzed using a Lotus 123 spreadsheet for storing data and analyzed using the statistical program Instat (GraphPad Software Inc., San Diego, CA).

\section{RESULTS}

\section{Developmental Milestones and Other Preliminary Observations}

The length of gestation in dams receiving the MAO-Is was significantly longer than that in the saline-treated animals (22.0 days versus 23 days $p<.02$; Fisher's ex- 
act test); however, the litter sizes were the same. There were no significant differences in the other developmental milestones: eye opening, incisor eruption, or olfactory responses in either the MAO-I-birth group, or the MAO-I-sac group.

Both MAO-I treatment groups gained weight significantly more slowly than their respective control group. Additionally, the deficit in weight gain was the same, regardless of how long the MAO-Is were administered (Figure 1). On observation, it appeared that the MAO-I-treated pups were nursed less frequently than the control pups, and were not taken into the nest by their dams. Interestingly, even when cross-fostered, saline dams did not nurture, or nurse an MAO-I treated pup. Conversely, a dam who had been treated during pregnancy with MAO-Is would take a control pup into the nest and nurse it. This suggests that the failure to nurse or be nurtured was more a fault of the MAO-I treated pups than that of the dam. However, that the treated pups all attained developmental milestones on time (e.g., eye-opening, incisor eruption, olfaction, righting reflex) suggests that the behavioral and neurochemical changes observed were not solely due to nutritional deficits.

In addition to the quantified testing described below, we observed other behaviors in both MAO-I treated groups of animals. First, the animals displayed constant repetitive stereotypic behaviors. In the MAOI-sacgroup, this principally involved grooming the head between the ears, resulting in completely rubbing off the fur. Second, 17 out of 28 of the MAO-I-sac animals were observed to have seizures on PD 5 and/or PD 6, varying in intensity from overall twitches to complete

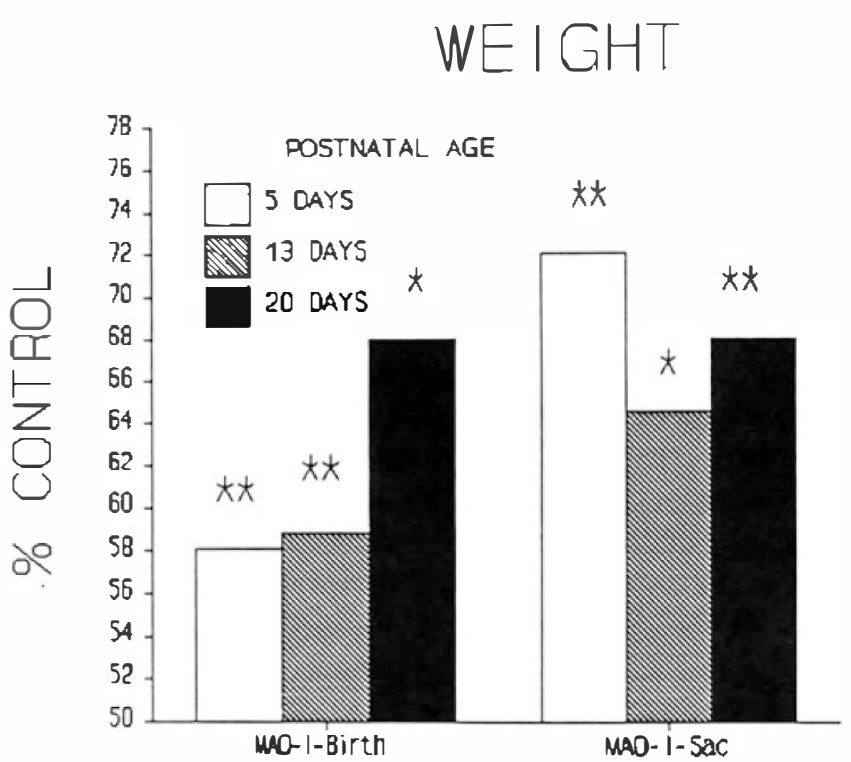

Figure 1. Weight of pups in the two treatment groups over time, as compared to their respective controls $(n=28$ at PD $5 ; n=18$ at PD 13, and $n=8$ at PD 20).

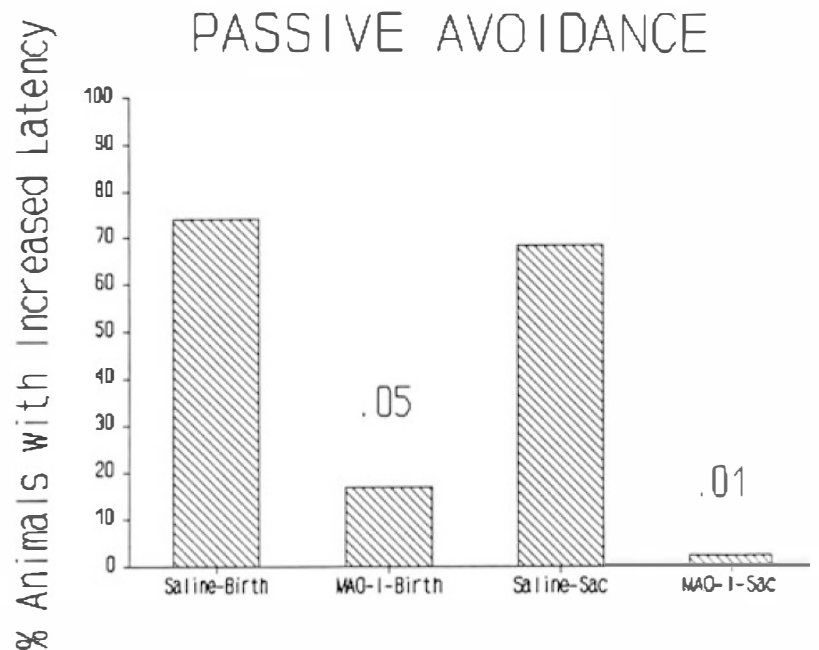

Figure 2. Passive avoidance in treated animals and their respective controls. Data are expressed as percent of animals increasing the latency to escape from the first chamber of a passive avoidance apparatus. Data were calculated using Fisher's exact test ( $n$ for each group $>8$ ).

myoclonic seizures. Third, both groups were very aggressive, making them difficult to handle, and they bit the investigators on several occasions. Finally, the MAO-I-sac animals acquired an opaque film in their eyes and did not respond to a visual stimulus (a mouse). This apparent blindness had a mean onset of 37 days.

\section{Behavioral Studies}

There were no significant differences in measures of catalepsy or time spent in the dark (percent light/ dark).

Passive Avoidance. Both groups of MAO-I treated animals showed significant deficits in meeting the criteria for passive avoidance. MAO-I-birth (1/8) versus control (9/12), $p<.05$ (Fisher's exact test), and MAO-Isac $(1 / 15)$ versus control (7/11), $p<.01$ (Fisher's exact test) (Figure 2).

Open Field. On PD 16, MAO-I-birth animals $(n=10)$ were not significantly different from their controls $(n=$ 6); however, MAO-I-sac animals were significantly more active than their controls $(63.0 \pm 19.5[n=11]$ versus $28.8 \pm 4.7[n=10], p<.03)$.

On PD 30, MAO-I-birth animals were significantly more active than controls $(74.6 \pm 5.6[n=10]$ versus $45.0 \pm 10.2[n=6], p<.02)$ as were the MAO-I-sac animals $(88.6 \pm 9.4[n=5]$ versus $66.3 \pm 2.1[n=6]$, $p<.03)$. These data are in Figure 3.

\section{Neurochemical Analysis}

${ }^{3}$ H-Paroxetine: Serotonin Uptake Sites. Both groups of MAO-I treated animals showed significant changes 
POSTNATAL DAY 16

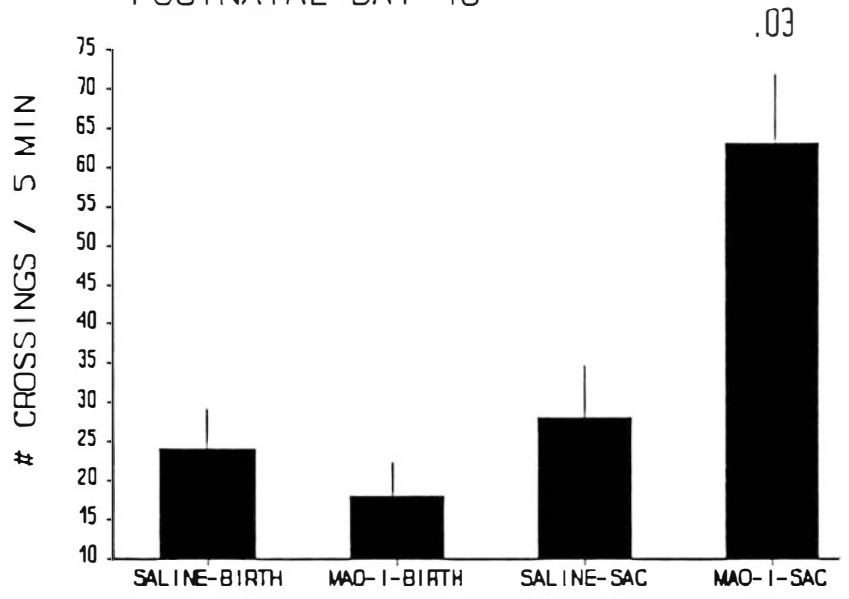

POSTNATAL DAY 30

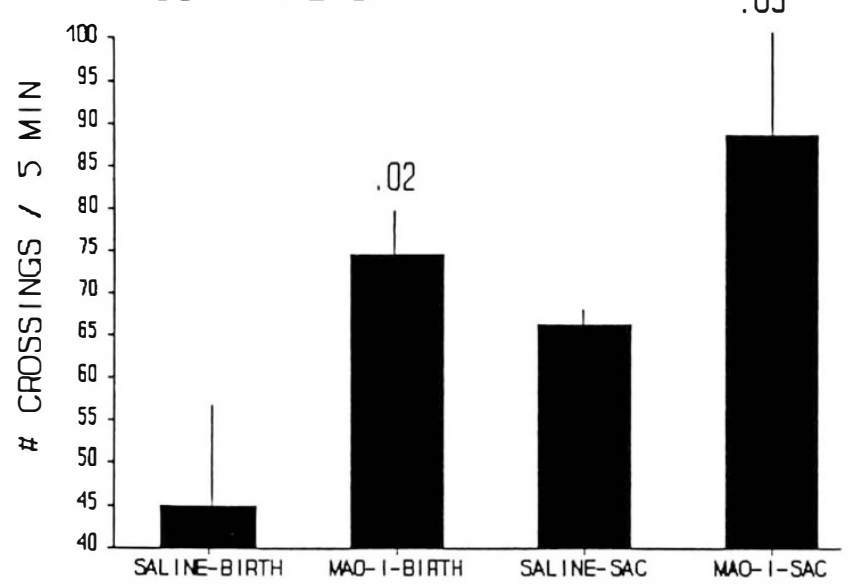

Figure 3. Open field activity in treated and control pups at PD 16 and 30. Data are expressed as number of lines crossed per five $\min (n>11$ at PD 16 , and $n>9$ at PD 30$)$.

in serotonin terminal density as measured by ${ }^{3} \mathrm{H}-$ paroxetine binding. Data was analyzed by a two-tailed, unpaired $t$-test with four animals in each group.

The MAO-I-birth animals showed significantly higher terminal density in hippocampus on PD $5(p<$ $.01)$, in caudate on PD $5(p<.03)$, and $30(p<.05)$. In cortex, these animals showed significantly less terminal density at PD $5(p<.04)$, and $30(p<.001)$, but an increased density at PD $15(p<.01)$.

The MAO-I-sac animals showed significantly elevated terminal density at PD 5 in caudate $(p<.01)$, and hippocampus $(p<.02)$. In cortex, these animals also showed significantly reduced serotonin terminal density at PD $5(p<.02)$. These data are in Figure 4.

${ }^{3}$ H-GBR 12935: Dopamine Uptake Sites. Neither treatment group showed significant changes in either terminal region at any timepoint.
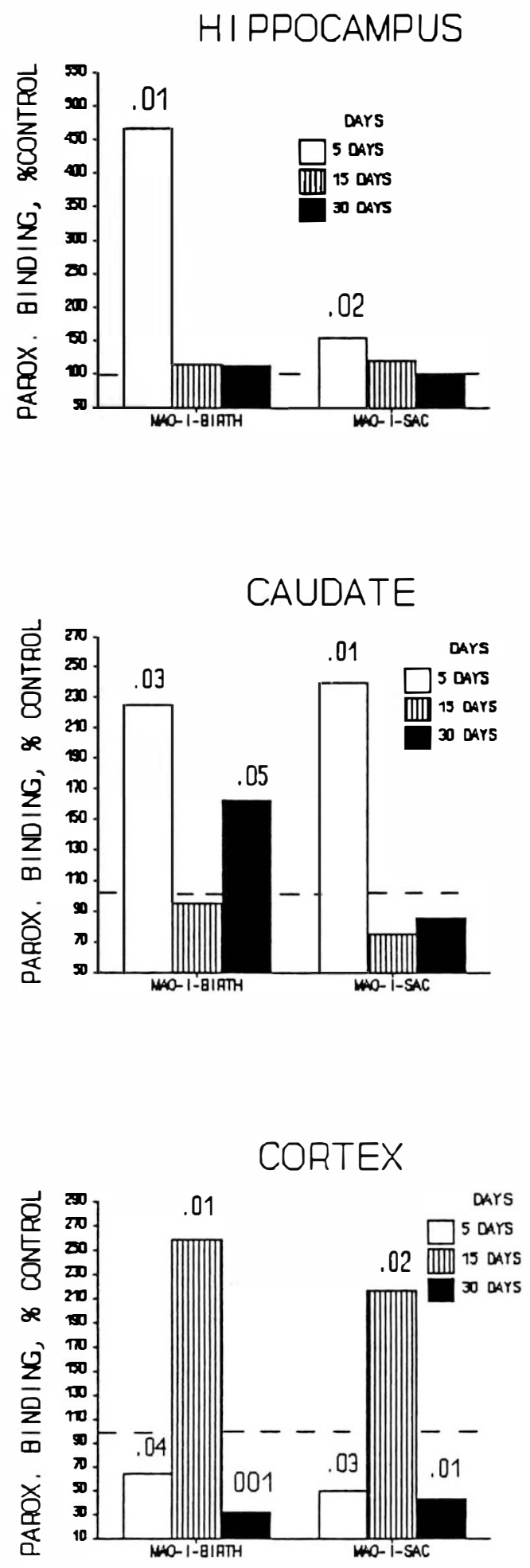

Figure 4. ${ }^{3} \mathrm{H}$-paroxetine binding to three regions of rat brain. The values are expressed as percent of the $B_{\max }$ values of the appropriate control $(n=4)$.

MAO Activity. The activity of MAO was significantly decreased at PD 5 in the animals receiving continual inhibitors $(118 \pm 54[n=3]$ versus $306 \pm 56[n=4]$ pmoles $/ \mathrm{min} / \mathrm{mg}, p<.05)$. The animals that had the in- 
hibitor stopped at birth showed recovery of activity with no significant difference from control $(259 \pm 69[n=4])$.

Sex Differences. None of the measures was influenced by sex of the pup.

\section{DISCUSSION}

Many monoamine neurotransmitters, including dopamine and serotonin, are important in regulation of brain development prior to assuming their roles as transmitters in the mature brain. In the rat and human fetus, MAO-A and MAO-B are both present in high levels by birth, and are an integral component of monoamine metabolism throughout brain development. Therefore, any factor that would influence the activity of this enzyme during development would indirectly influence development. The purpose of this study was to determine how profound this influence is, in terms of terminal development and behavior, how long-lasting the effects are, and if these changes can be overcome once the function of MAO is allowed to return to normal.

Our results show, that even with MAO activity only reduced to $50 \%$ of control levels, the influence is profound and longlasting. Additionally, in many of the measures, the effects appear to be the same whether or not the enzyme is allowed to recover. It is possible that the animals in which treatment was stopped were more impaired because the brain had adapted to the decreased MAO, and returning the levels to normal was a further insult to the system.

MAO-Is increase the levels of a number of brain substances, including serotonin, dopamine, noradrenaline, and the trace amines, phenethylamine and tyramine. Presumably all of these would have been elevated in the treated animals, and could have caused the brain changes and the behavioral changes. Insufficient information is known about the role of the trace amines in development, but serotonin, dopamine, and noradrenaline are all highly influential.

The most pronounced neurochemical change in the animals was in the serotonin innervation density. We have previously reported that the amount of ${ }^{3} \mathrm{H}$ paroxetine binding in the maturing brain increases to a peak value, and then decreases to a plateau level when the brain reaches a mature state (Whitaker-Azmitia et al. 1991). This may represent the maturational stages of neuronal overgrowth, and subsequent synaptic elimination. In the MAO-I treated animals, the same pattern was evident in the cortex, but temporally delayed. This is evident in the pronounced decrease in ${ }^{3} \mathrm{H}$ paroxetine binding in the cortex of five-day-old, $\mathrm{MAO}$ I-treated pups, an increase at PD 15, and a decrease at PD 30. At PD 5, both treatment groups showed reciprocal changes in serotonin terminal density in cortex and caudate (i.e., cortical levels were reduced whereas cau- date was increased). This may represent the developmental stage of pruning, whereby a neuron will overproduce terminals in one area if it is underproducing in another. We are currently repeating our studies, using serotonin immunocytochemistry to more completely characterize the changes in serotonin terminals.

Changes in the serotonin system during development have two effects on the resulting structure of the mature brain. First, serotonin autoregulates its own development, and thus changes in serotonin levels during development alter the final morphology of the serotonin system (Whitaker-Azmitia and Azmitia 1986). Second, the serotonin system is involved in regulation of the maturation of cells in the terminal regions to which it projects (Lauder 1983). This action may be through the release of the growth factor, $S-100 \beta$, from astrocytes in the terminal fields (Whitaker-Azmitia and Azmitia 1990). This suggests that the MAO-I treated animals will have cortical abnormalities worth further investigating.

That we found no changes in the terminal density of the dopaminergic system in caudate or cortex is not surprising, because this system does not appear to regulate its development as the serotonin system does (Van Muiswinkel et al. 1993).

Most basic developmental milestones were not affected by the MAO-I treatment. For example, eyeopening and incisor eruption developed on schedule, as did righting reflexes and response to a noxious odor; however, there were significant changes in weight gain in both treatment groups. This change may explain the delayed parturition in the treated mothers. This effect occurred irrespective of the treatment duration. Much of this could be due to the decreased nursing behavior of the pups. Suckling and nursing behavior is profoundly influenced by serotonin effects as is appetite; however, we also observed that the pups were not gathered in the nest for nursing, which suggests changes in maternal-offspring interactions. Failure to be nurtured could be due to the lack of such signals as emitting an ultrasonic cry (Winslow and Insel 1993), or due to elevated body temperature (Leon et al. 1978).

In the passive avoidance paradigm, both treatment groups showed significant deficits in avoiding the negative reenforcer. Passive avoidance behavior is a highly sensitive, easy-to-perform behavioral test, commonly used as a model of learning and memory, although it may serve as a measure of anxiety and impulsivity. Pain perception is a common, confounding component of this behavior. Because we have previously found that prenatal manipulations of the serotonin system can affect development of pain pathways (Bell et al. 1992), we used the less traditional method of forced swim as the negative reinforcer.

The learning and memory component of the behavior is assumed to reside in the hippocampus. A 
number of neurotransmitter systems are thought to be involved, including serotonin (Altman and Normile 1986), and acetylcholine (Riekkinen et al. 1991). At the time of the passive avoidance deficits in the treated animals, there are no apparent changes in the hippocampal serotonin innervation. This suggests that the change is not due to serotonin, or that learning and memory changes are not responsible. It is possible that the change in passive avoidance is due to changes in anxiety; however, this is also not probable because the test for anxiety (percent light/dark) showed that anxiety was not evident in the treated animals.

The final possibility is that the behavior is showing changes in impulsivity, the inability to inhibit negatively-reenforced behaviors. This is a particularly attractive hypothesis because serotonin deficits are commonly believed to be associated with impulse disorders in humans (Insel et al. 1990; Stein et al. 1993). Lowered MAO activity has also been found in both children and adults with impulse disorders (Shekim et al. 1986; Klinteberg et al. 1992). A recent study has found a defect in the MAO-A gene in male members of a Dutch family, who have violent impulsive behavior (Brunner et al. 1993).

The animals, as well, had significant changes in open field activity. The animals treated throughout life showed significantly increased activity at both timepoints tested, whereas the MAO-I-birth group only showed the deficits at 30 days; however, the behavioral changes do not strictly correlate with the changes in serotonin terminal density. For example, increased open field activity is seen at postnatal day 15 and day 30 in the MAO-I-sac animals, even though serotonin terminal density is increased in cortex at day 15 , and decreased in cortex at day 30 . Complex behaviors such as these are not always explained by a single neurochemical change. In addition, adult behaviors can be dependent upon chemical imprinting during development; the level of a neurotransmitter has to be at the appropriate level at a certain developmental stage for subsequent behaviors to develop properly, meaning that the neurochemical and behavioral change do not need to coexist (Whitaker-Azmitia 1992).

There are several human states this research may be relevant to. As previously noted, there is decreased MAO-B activity in hyperactive boys (Shekim et al. 1986). In that report, the enzyme was reduced to about $40 \%$ of the activity in a control population. Based on our findings with an approximate $50 \%$ reduction of MAO activity, this enzyme change in the human population would have significant behavioral consequences.

The results may also be relevant to the study of Norrie's disease, an X-linked recessive disorder which is usually first diagnosed when a child is found in early infancy to be blind (Norrie 1927). In addition, the children are sometimes mentally retarded, and may also show a progressive hearing loss. In cases with chromosomal deletions involving the Norrie's disease gene, seizures are common, and the children may show repetitive stereotypical behavior, including those that can become self-injurious, such as headbanging. In general, the disorder is characterized by a progressive worsening of symptoms, and the life expectancy is only thirty years. The gene for Norrie's disease has been localized to the proximal short arm of the X-chromosome with close linkage to the region containing genes for MAO-A and MAO-B (Gal et al. 1986; Donnai et al. 1988). Some atypical Norrie's disease patients have been shown to have a deletion of this region, and there is a functional and structural absence of MAO-A and MAO-B (Sims et al. 1989) with the expected neurochemical changes (Murphy et al. 1990).

The animals in the MAO-I-sac group had a striking resemblance to this human disorder. In addition to the behavioral changes, we observed that the animals were highly stereotypic and showed seizure activity. Eventually, the animals appeared to become blind.

Finally, our results may have relevance as a model of teratogenicity of MAO-Is. Although this class of antidepressants has not been as commonly used as others, the introduction of reversible MAO-Is may cause an increase in their use (Rudorfer 1992; Silverstone 1992). Our results indicate the drugs should be avoided in young women who may become pregnant.

\section{ACKNOWLEDGMENTS}

The authors appreciate the helpful suggestions of Dr. Dennis Murphy and Dr. X. Breakefield in designing the experiments and writing the manuscript, and Dr. Katherine Sims and Ms. Christina Fleet for the MAO assays (funded by NINDS grant \#21921).

\section{REFERENCES}

Altman HJ, Normile HJ (1986): Enhancement of memory of a previously learned aversive habit following pre-test administration of a variety of serotonergic antagonists in mice. Psychopharmacology 90:24-27

Bell JT, Zhang X, Whitaker-Azmitia PM (1992): 5- $\mathrm{HT}_{3}$ Receptor-active drugs alter development of spinal serotonergic innervation: lack of effect of other serotonergic agents. Brain Research 571:293-297

Brunner HG, Nelen MR, van Zandvoort P, Abeling NGGM, van Gennip AH, Wolters EC, Kuiper MA, Ropers $\mathrm{HH}$, van Oost BA (1993): X-linked borderline mental retardation with prominent behavioral disturbance: phenotype, genetic localization, and evidence for disturbed monoamine metabolism. Am J Hum Genet 52:1032-1039

Donnai D, Mountford RC, Read AP (1988): Norrie disease resulting from a gene deletion: Clinical features and DNA studies. J Medical Genetics 25:73-78 
Edelstein SB, Breakefield XO (1986): Monoamine oxidases A and $B$ are differently regulated by glucocorticoids and "aging" in human skin fibroblasts. Cell Mol Neurobiol 6:121-150

Fowler JB, Macgregor RR, Wolf AP, Arnett CD, Dewey SL, Schlyer D, Christman D (1987): Mapping human brain monamine oxidase $A$ and $B$ with ${ }^{11} \mathrm{C}$-labelled suicide inactivators and PET

Gal A, Wieringa B, Smeets DF, Bleeker-Wagemakers LM, Ropers HH (1986): Submicroscopic interstitial deletion of the $X$ chromosome explains a complex genetic syndrome dominated by Norris disease. Cytogenet Cell Genet 42:219-224

Garrick NA, Murphy DL (1980): Species differences in the deamination of dopamine and other substrates for monoamine oxidase in brain. Psychopharmacology 72 : 27-33

Insel T, Zohar J, Benkelfat C, Murphy DT (1990): Serotonin in obsessions, compulsions, and the control of aggressive impulses. Whitaker-Azmitia PM, Peroutka SJ (eds.), The Neuropharmacology of Serotonin, New York Academy of Sciences, pp. 574-586

Klinteberg B, Hallman J, Oreland L, Wirsen A, Levander SE, Schalling D (1992): Exploring the connections between platelet monoamine oxidase activity and behavior. II. Impulsive personality without neuropsychological signs of disinhibition in air force pilot recruits. Neuropsychobiology 26(3):136-145

Lauder JM (1983): Hormonal and humoral influences on brain development. Psychoneuroendocrinology 8:121-155

Leon M, Croskerry PG, Grant GK (1978): Thermal control of mother-young contact. Physiol Behav 21:793-811

Murphy DL (1978): Substrate-selective monoamine-oxidasesinhibitor, tissue, species and functional differences. Biochem Pharm 27(15):1889-1893

Murphy DL, Sims KB, Karoum F, de la Chapelle A, Norio R, Sankila E-M, Breakefield XO (1990): Marked amine and amine metabolitechanges in Norrie Disease patients with an X-chromosomal deletion affecting monamine oxidase. J Neurochem 54:242-247

Norrie G (1927): Cause of blindness in children. Acta Ophthamol 5:357-386

Riekkinen M, Riekkinen P, Riekkinen P JR (1991): Comparison of quisqualic and ibotenic acid nucleus basalis magnocellularis lesions on water-maze and passive avoidance performance. Brain Research Bulletin 27:119-123
Rudorfer, MV (1992): Monoamine oxidase inhibitors: Reversible and irreversible. Psychopharmacol Bull 28(1):45-57

Shekim WO, Bylund DB, Alexson J, Glaser RD, Jones SB, Hodges K, Perdue S (1986): Platelet MAO and measures of attention and impulsivity in boys with attention deficit disorder and hyperactivity. Psychiatry Res 18:179-188

Sherif F, Mallman J, Oreland L (1992): Low platelet 2-amino butryate transaminase and monoamine oxidase in chronic alcoholics. Alcohol Clin Exp Res 16(6):1014-1020

Silverstone T (1992): New aspects in the treatment of depression. Int Clin Psychopharmacol. 6(suppl 5):41-44

Sims KB, de la Chapelle A, Norio R, Sankila EM, Hsu Y-PP, Rinehart WB, Corey TJ, Ozelius L, Powell JF, Bruns G, Gusella JF, Murphy DL, Breakefield XO (1989): Monoamine oxidase deficiency in males with an $\mathrm{X}$ chromosome deletion. Neuron 2:1069-1076

Stein DJ, Hollander E, Liebowitz MR (1993): Neurobiology of impulsivity and the impulse control disorders. J Neuropsychiatry Clin Neurosci 5(1):9-17

Van Muiswinkel FI, Drukarch B, Steinbusch HW, Stodf JC (1993): Chronic dopamine $D_{2}$ receptor activation does not affect survival and differentiation of cultured dopaminergic neurons: Morphological and neurochemical observations. J Neurochemistry 60(1):83-89

Whitaker-Azmitia PM, Azmitia E (1986): Autoregulation of fetal serotonergic neuronal development: Role of high affinity serotonin receptors. Neurosci (Lett) 67:307-312

Whitaker-Azmitia PM, Azmitia EC (1990): Stimulation of astroglial $5-\mathrm{HT}_{1 \mathrm{a}}$ receptors releases the serotonergic growth factor, protein S-100, and alters astroglial morphology. Brain Res 528:155-158

Whitaker-Azmitia PM, Quartermain D, Shemer AV (1991): Prenatal treatment with SKF 38393, a selective D-1 receptor agonist: Longterm consequences on ${ }^{3} \mathrm{H}$-paroxetine binding and on dopamine and serotonin receptor sensitivity. Dev Brain Res 57:181-187

Whitaker-Azmitia, PM(1992): Role of serotonin and otherneurotransmitter receptors in brain development: Basis for developmental pharmacology. Pharm Rev 43:553-561

Wurtman RJ, Axelrod J (1963): A sensitive and specific assay for the estimation of monoamine oxidase. Biochem Pharmacol 12:1439-1441

Winslow JT, Insel TR (1993): The infant rat separation pardigm: A novel test for novel anxiolytics. Trends Pharm Sci 12(11):402-404 